\title{
Aplicação da análise de confiabilidade para avaliação de estações de tratamento de esgoto no estado do Ceará
}

\author{
Application of reliability analysis for evaluation of sewage \\ treatment plants in the state of Ceará
}

Aplicación del análisis de fiabilidad para evaluación de
estaciones de tratamiento de desagües en el estadodel Ceará
Application de l'analyse de fiabilité pour l'évaluation de station d'épuration dans l'état de Ceará

Francisco de Assis Martins Ponce (iD fcodeassismartins@usp.br Universidade de São Paulo (USP)

Silvio Luiz de Sousa Rollemberg iD silviorollemberg@gmail. com Universidade de Federal do Ceará (UFC)

Andre Gadelha de Oliveira (iD andregadelha@unifor.br Universidade de Fortaleza (Unifor)

\section{Resumo}

A confiabilidade é a probabilidade de um item exercer sua função de forma adequada, em conformidade com condições específicas, por um período determinado de tempo. Sendo assim, torna-se essencial que os processos de tratamento de esgotos sejam avaliados em relação à confiabilidade, fornecendo informações que permitem subsidiar a seleção de um determinado sistema de tratamento, além de permitir a avaliação do desempenho real de uma ETE. Nesse contexto, esta pesquisa investigou 3 (três) diferentes rotas de tratamento de esgoto de ETEs operadas pela Companhia de Água e Esgoto do Ceará (Cagece) avaliando-se os resultados de eficiência e testes de confiabilidade (considerando valor de 95\%). Observou-se que o sistema composto por reator UASB acompanhado de filtro submerso aerado (FBAS) alcançou um efluente de melhor qualidade em termos de remoção de DQO e melhor homogeneidade dos dados. Por outro lado, a rota de lodos ativados por aeração prolongada obteve o melhor desempenho com relação à remoção de amônia, comportamento esperado por esse tipo de tecnologia. Por fim, verificou-se que a análise de confiabilidade é uma importante ferramenta a ser aplicada no monitoramento de ETEs, ressaltando a importância desses estudos para a tomada de decisão na escolha tecnológica de novas estações.

Palavras-chave: Análise de confiabilidade. Desempenho das estações de tratamento de esgotos. Padrões de lançamento.

\section{Abstract}

Reliability is the probability that an item performs its function adequately, in accordance with specific conditions, for a set period of time. Therefore, it is essential that the processes of sewage treatment be evaluated in relation to reliability, thus providing information that allows subsidizing the selection of a particular treatment system, in addition to allowing the evaluation of the actual performance of a WWTP. In this context, this research investigated three (3) different sewage treatment routes of WWTPs operated by the Company of Water and Sewage of Ceará (CAGECE) evaluating the efficiency results and reliability tests (considering a value of $95 \%$ ). It was observed that the system composed of UASB Reactor accompanied by Submerged Aerated Filter (SAF), achieved a better-quality effluent in terms of COD removal and better data homogeneity. On the other hand, the route of Extended Aeration Activated Sludge Process obtained the best performance in relation to the ammonia removal, behavior expected by this type of technology. Finally, it was verified the reliability 
analysis is a tool to be applied in the monitoring of WWTPs, emphasizing the importance of these studies for the decision making for the technological choice of new plants design.

Keywords: Reliability analysis. Wastewater treatment plants performance. Release patterns.

\begin{abstract}
Resumen
La fiabilidad es la probabilidad de un ítem ejercer su función de forma adecuada, de acuerdo con las condiciones específicas, por un determinado período de tiempo. Así, es esencial que los procesos de tratamiento de desagües sean evaluados en relación a la fiabilidad, ofreciendo informaciones que permiten subsidiar la selección de un determinado sistema de tratamiento, además de permitir la evaluación del rendimiento real de una ETD. En este contexto este trabajo investigó 3 (tres) distintas rutas de tratamiento de desagües de ETDs operada por la Compañía de Agua y Desagüe del Ceará (CAGECE) evaluando los resultados de eficiencia y pruebas de fiabilidad (considerando valor de 95\%). Se observó que el sistema compuesto por reactor UASB acompañado de Filtro Inmerso Aireado (FIA), logró un efluente de mejor calidad en términos de remoción de DQO y mejor homogeneidad de los datos. Por otro lado, la ruta de Limo Activado por aireación prolongada obtuvo el mejor rendimiento con relación a la remoción de amonio, conducta esperada por este tipo de tecnología. Finalmente, se verificó que el análisis de fiabilidad es una importante herramienta a ser aplicada en el control de ETDs, resaltando la importancia de estos estudios para la toma de decisión para elección tecnológica de nuevas estaciones.
\end{abstract}

Palabras-clave: Análisis de fiabilidad. Rendimiento de las estaciones de tratamiento de desagües. Referencias de lanzamiento.

\title{
Résumé
}

La fiabilité est la probabilité qu'un élément puisse exercer sa fonction de manière adéquate, conformément aux conditions spécifiques, pendant une période donnée. Par conséquent, il est essentiel que les processus d'épuration des eaux usées soient évalués en fonction de leur fiabilité. Cela fourni des informations qui permettent sélectionner un système d'épuration particulier et permettent aussi l'évaluation de la performance réelle d'une STEP. Dans ce contexte, cette recherche a examiné trois voies différentes de d'épuration des eaux usées opérées par la Compagnie des Eaux et Égouts de l'état de Ceará (CAGECE) en évaluant les résultats d'efficacité et les tests de fiabilité (en considérant une valeur de 95\%). Il a été observé que le système composé d'un réacteur digesteur anaérobie à flux ascendant (UASB) accompagné d'un biofiltre aéré à flux descendant (BAFs) a permis d'obtenir un effluent de meilleure qualité chez l'élimination de la DCO et aussi une meilleure homogénéité des données. D'autre part, la voie des boues activées par d'aération prolongée a obtenu les meilleures performances en matière d'élimination de l'ammoniac. Cela est le comportement attendu chez ce type de technologie. Finalement, il a été vérifié que l'analyse de fiabilité est un outil important à appliquer dans la surveillance des STEP. On souligne, donc, l'importance de ces études pour le choix de la technologique dans les nouvelles stations.

Mots-clés: Analyse de fiabilité. Performance des stations d'épuration des eaux usées. Libérations des eaux usées.

\section{Introdução}

Segundo Metcalf e Eddy (2016), a confiabilidade de uma estação de tratamento ou de um determinado processo pode ser definida como a probabilidade de desempenho adequado durante um período de tempo especificado, em condições especificadas, ou em termos de desempenho da estação, como a porcentagem de tempo em que as concentrações do efluente atinjam os requisitos de emissão de efluentes.

A confiabilidade de sistemas é dividida em duas grandes categorias: a confiabilidade de projetos e a confiabilidade operacional. A primeira categoria inclui o estudo de itens como análise de confiabilidade, 
Aplicação da análise de confiabilidade para avaliação de estações de tratamento de esgoto no estado do Ceará

verificação de projetos e análise de testes de confiabilidade; enquanto segunda trata da análise de falhas, registros de operação, ações corretivas, entre outras.

Em termos de desempenho/performance de uma estação de tratamento de efluentes (ETE), a confiabilidade pode ser entendida como a porcentagem de tempo em que se conseguem as concentrações esperadas no efluente para cumprir com os padrões de lançamento, portanto, uma ETE será completamente confiável se não houver falhas no desempenho, isto é, se não tiver violação dos limites preconizados pelas legislações ambientais. Sendo assim, a falha do processo de tratamento ocorrerá sempre que o padrão de lançamento for excedido (OLIVEIRA; VON SPERLING, 2007).

Ainda segundo Oliveira e von Sperling (2007), a confiabilidade de uma ETE é baseada no conhecimento do comportamento do processo das variações na qualidade do efluente tratado. A estação de tratamento deve ser naturalmente projetada para produzir uma concentração média do efluente abaixo dos padrões de lançamento, determinando uma concentração média que garanta que a concentração do efluente estará abaixo de certo valor, com um determinado nível de confiabilidade. Dessa forma, Niku et al. (1979) desenvolveram um método que relaciona a concentração média do constituinte (valor de projeto) com os valores limites a serem cumpridos baseando-se em análises probabilísticas. Sendo assim, estabeleceu-se que uma determinada concentração média garanta que a concentração de um efluente qualquer esteja abaixo de um dado valor, mantendo um nível de confiabilidade.

Nesse contexto, um importante parâmetro no teste é o coeficiente de confiabilidade, uma grandeza que correlaciona valores de concentrações médias diretamente com o padrão de lançamento com base em uma análise probabilística. Exemplificando: se um determinado parâmetro deveria atingir uma concentração de 100 $\mathrm{mg} / \mathrm{L}$, que deve ser cumprido $95 \%$ do tempo, a estação deve ser projetada e/ou operada para produzir um efluente com concentração de modo que venha a obedecer a legislação, mesmo com as variações operacionais na estação. Existem três tipos de variação que podem alterar os índices de confiabilidade: (i) variabilidade da vazão e características da vazão de esgoto, (ii) variabilidade inerente de processos de tratamento de esgotos e (iii) variabilidade causada por problemas mecânicos, erros de projeto e falhas operacionais (METCALF; EDDY, 2016).

Bastos et al. (2006) investigaram a performance de uma ETE antes e depois de procedimentos de melhoria e, com isso, a análise de desempenho permitiu constatar defeitos de projeto, processos ou de monitoramento operacional, além de facilitar orientações para eventuais procedimentos de melhoria.

Dessa forma, este trabalho avaliou os coeficientes de confiabilidade de três diferentes rotas tecnológicas de tratamento de esgoto, estimando-se a confiabilidade de cada ETE. Para tal, foi utilizado o método desenvolvido por Niku et al. (1979).

A relevância desta pesquisa se dá por vários fatores: (i) os estudos de confiabilidade aplicado à tecnologias de tratamento de esgoto ainda são poucos, sendo necessária a existência de trabalhos que proporcionem melhor entendimento da área; (ii) a análise de confiabilidade pode ser utilizada como avaliação do desempenho de um ETE, além de auxiliar na tomada de decisão para escolha de rotas tecnológicas de tratamento de esgoto, e (iii) o estudo de confiabilidade pode auxiliar na identificação de possíveis causas para baixos rendimentos de plantas de ETEs.

\section{Metodologia}

\subsection{ETEs estudadas}

Para realização da pesquisa, foram utilizadas 3 (três) ETEs operadas pela Companhia de Água e Esgoto do Ceará (Cagece). Para a seleção das ETEs, a qual ocorreu em conjunto com a concessionária, foram seguidos os seguintes passos: (i) as ETEs operadas pela companhia foram divididas em grupos (clusters) de acordo com a tecnologia empregada; (ii) após a divisão dos grupos, foram selecionadas (de cada grupo) as ETEs que possuíam melhor desempenho em termos de remoção de poluentes; (iii) por fim, foi selecionada uma ETE de cada rota tecnológica. 
A ETE 1 é composta por dois reatores tipo UASB seguido de dois filtros biológicos submersos aerados (FBAS). Nessa ETE, inicialmente, ocorre o tratamento preliminar com gradeamento, caixa de areia com medidor de vazão, para, em seguida, o esgoto passar pelo tratamento biológico. Após passar pelo tratamento biológico anaeróbio dos dois reatores UASB, o efluente segue para os filtros aerados submersos, onde é tratado por bactérias que atuam com processo aeróbio, e esse processo se dá com auxílio de aeração através de bombas. O sistema de aeração do FBAS é composto por um soprador de ar e um painel de comando, o qual é ligado durante três horas pela manhã (das $8 \mathrm{~h}$ às $11 \mathrm{~h}$ ) e por mais três horas à tarde (das $14 \mathrm{~h}$ às $17 \mathrm{~h}$ ) pelo operador.

Figura 1 - Fluxograma da ETE 1: Reator UASB + FBAS.

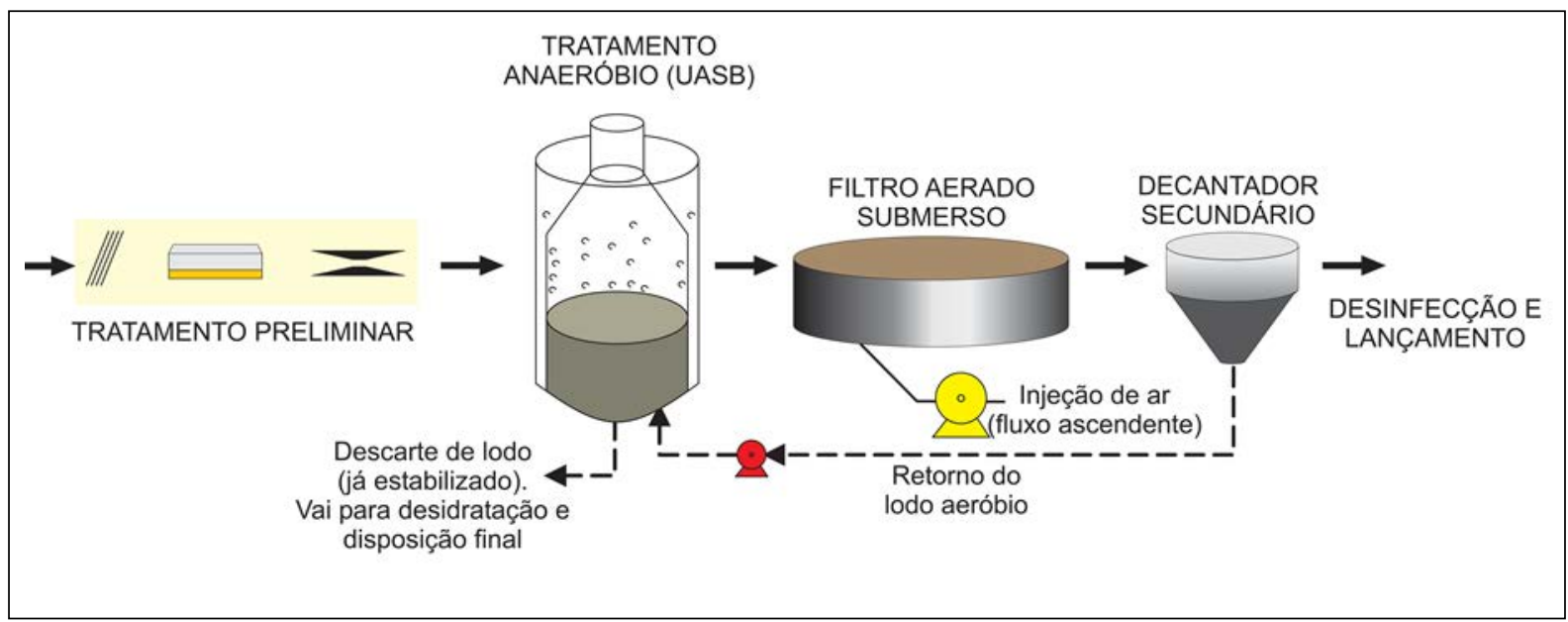

Fonte: Elaborado pelos autores, 2019.

AETE 2 é composta por um decanto digestor (DD) seguido por um filtro anaeróbio (FA). Ressalta-se que essa estação também é composta por um pré-tratamento com gradeamento e desarenador. Na estação em questão, com essa tecnologia adotada, o efluente final após a etapa da desinfecção com cloro é descartado em um corpo hídrico, enquanto o lodo é disposto em leitos de secagem para posterior disposição final. No caso, aterro sanitário. A Figura 2 mostra o esquema da ETE 2.

Figura 2 - Fluxograma da ETE 2: DD + FA.

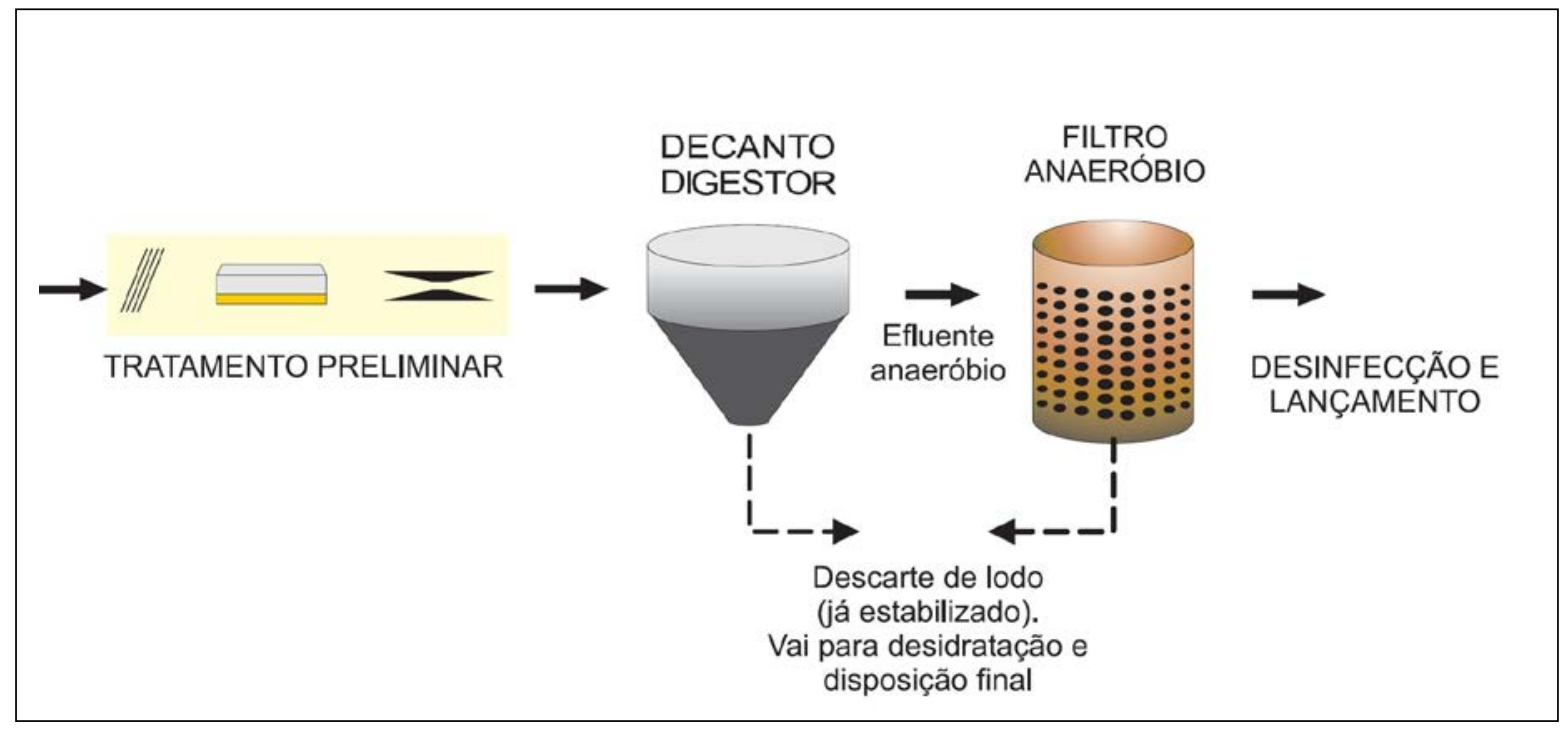

Fonte: Elaborado pelos autores, 2019. 
AETE 3 adota o sistema de lodos ativados por aeração prolongada (LAAP), com reator biológico seguido por um decantador secundário. Inicialmente, há o tratamento preliminar com gradeamento e desarenador com medidor de vazão. Após isto, o efluente é encaminhado para um poço de sucção com bomba submersível, onde é recalcado para o reator biológico e, então, recebe injeção de ar através de aeradores. Posteriormente, o efluente é direcionado para os decantadores secundários. O efluente tratado (sobrenadante do decantador secundário) segue para desinfecção (remoção de patógenos) e é encaminhado para um corpo hídrico receptor. Já o lodo retido no decantador secundário possui dois destinos: uma parcela é recirculado para o tanque de aeração e a outra parcela é então adensada e desidratada (lodo excedente) para seguir para o aterro sanitário. Ressalta-se que não são projetados decantadores primários em sistemas de aeração prolongada para evitar a geração de alguma outra forma de lodo que venha a requerer posterior estabilização, já que o lodo do reator biológico se encontra estabilizado devido a recirculação do lodo gerado do decantador secundário para o reator biológico (Von Sperling, 2014). A Figura 3 mostra o esquemático da ETE 3.

Figura 3 - Fluxograma da ETE 3: Sistema de lodos ativados por aeração prolongada.

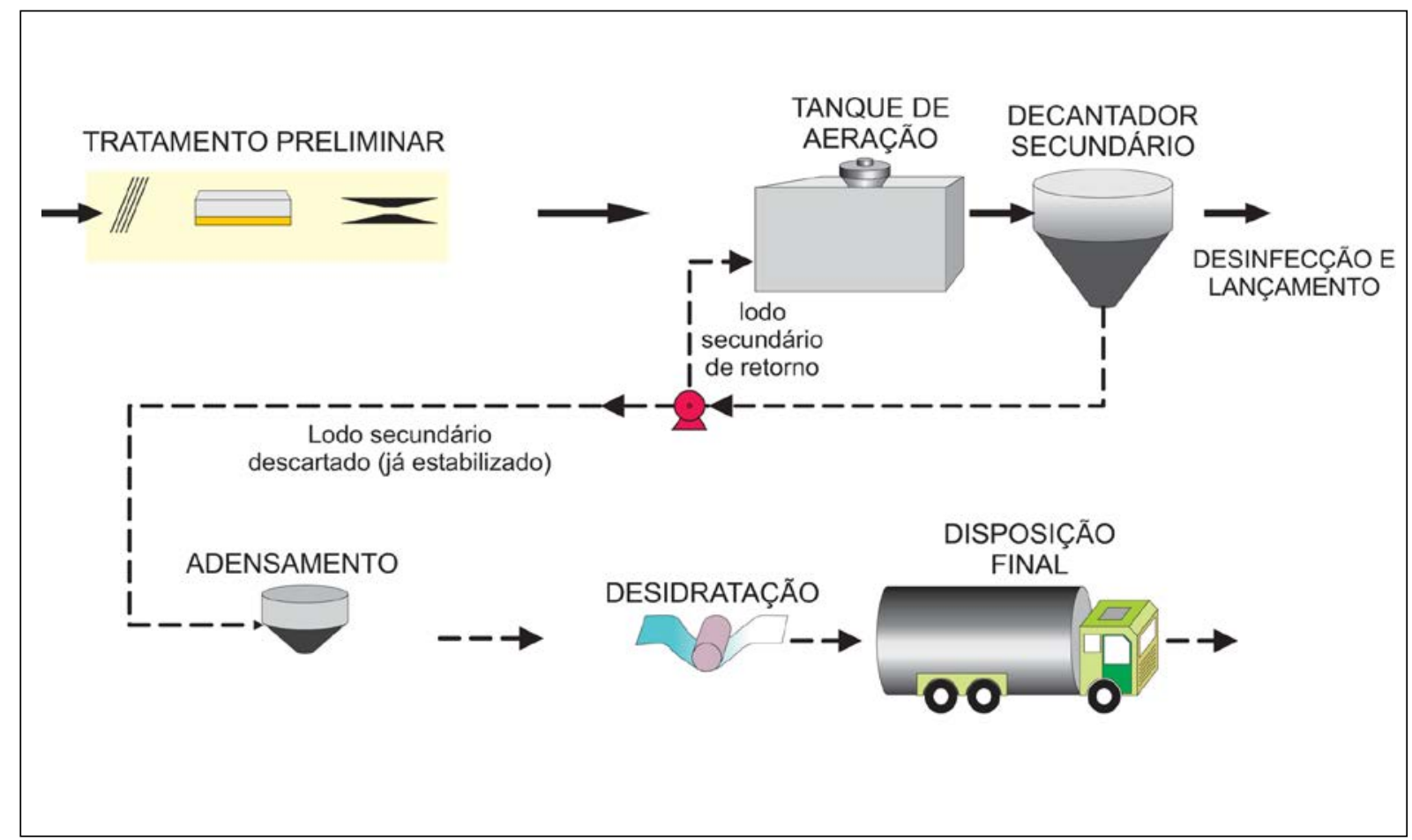

Fonte: Elaborado pelos autores, 2019.

\subsection{Análise de confiabilidade}

Primeiramente, buscou-se determinar o desvio padrão $\left(\sigma_{x}\right)$ e a média de distribuição $\left(\mu_{x}\right)$ de cada parâmetro analisado. Após isto, encontrar os coeficientes de variação (CV) analisados neste estudo (Tabela 2) através da Equação 1 e calcular a variável normal reduzida para o nível de confiabilidade (95\%) conforme a Equação 2. Os CVs de cada parâmetro foram alcançados pela divisão do desvio padrão pela média da distribuição normal.

$$
\mathrm{CV}=\frac{\sigma_{x}}{\mu_{x}}
$$

Onde:

CV = coeficiente de variação; 
$\sigma_{x}=$ desvio padrão;

$\mu_{x}=$ média de distribuição.

Valendo-se das relações entre a lognormal e a distribuição normal, juntamente com poucas modificações algébricas, levando em consideração o coeficiente de variação (CV), a média de distribuição $\left(\mu_{x}\right)$ e o limite para cada parâmetro $\left(\mathrm{X}_{s}\right)$, os autores encontraram a Equação 2, que é de fácil utilização.

$$
Z_{1-\alpha}=\frac{\ln \mathrm{X}_{s}-\left[\ln \mu_{X}-\frac{1}{2} \ln \left(1+\mathrm{CV}_{x}^{2}\right)\right]}{\sqrt{\ln \left(1+\mathrm{CV}_{x}^{2}\right)}}
$$

Equação 2

Onde:

$Z_{1-\alpha}=$ variável normal reduzida correspondente à probabilidade de não excedência; $1-\alpha$;

$\mathrm{X}_{s}=$ padrão estabelecido pela legislação.

Um exemplo prático da Equação 2 para uma determinada ETE, por exemplo, em que as concentrações médias do efluente tenham valores de $25 \mathrm{mgL}^{-1}\left(\mu_{X}\right)$, com CV $=0,51$ e tomando em consideração o valor máximo permitido de $\mathrm{DBO}=60 \mathrm{mgL}^{-1}\left(\mathrm{X}_{s}\right)$, o percentil calculado é:

$$
Z_{1-\alpha}=\frac{\ln (60)-\left[\ln (25)-\frac{1}{2} \ln \left(1+0,51^{2}\right)\right]}{\sqrt{\ln \left(1+0,51^{2}\right)}}=2,054
$$

Levando em conta a Tabela 1, para $Z_{1-\alpha}=2,054$, o valor correspondente é de $98 \%$, significando, para essa determinada ETE, que o percentual de conformidade atendendo ao limite de descarga de DBO ( $\mathrm{X}_{s}=60$ $\mathrm{mgL}^{-1}$ ) esperado é de $98 \%$, com a estação mantendo as condições normais de operação (OLIVEIRA; VON SPERLING, 2008).

Tabela 1 - Valores padronizados da distribuição normal.

\begin{tabular}{c|c}
\hline Nivel de confiabilidade (\%) & $Z_{1-\alpha}$ \\
\hline 80 & 0,842 \\
\hline 90 & 1,282 \\
\hline 95 & 1,645 \\
\hline 98 & 2,054 \\
\hline 99 & 2,326 \\
\hline
\end{tabular}

Fonte: Adaptado de Niku et al. (1979).

Para etapa posterior, os coeficientes de confiabilidade (CDC), que relacionam o valor médio do parâmetro $\left(\mu_{X}\right)$ com o valor padrão ( $\left.X_{s}\right)$ para um determinado nível de confiabilidade (Oliveira, 2006), foram calculados por meio da Equação 3 para os parâmetros estudados (Tabela 2). Esses coeficientes foram desenvolvidos por Niku et al. (1979), podendo ser empregados para determinação de confiabilidade das ETEs, isto é, a partir do tempo que o valor de um parâmetro efluente da estação não ultrapassa um determinado valor padrão de referência (LOMBARD-LATUNE et al., 2018). Utilizou-se os CVs (Equação 1) e a variável normal reduzida $\left(Z_{1-\alpha}\right)$, calculados para cada parâmetro das três ETEs em questão. O CDC é definido baseado nos dados de origem, e não nos logaritmos dos dados ("OLIVEIRA; VON SPERLING, 2008). 


$$
\mathrm{CDC}=\sqrt{\left(\mathrm{CV}^{2}+1\right)} \cdot \exp \left[-Z_{1-\alpha} \sqrt{\ln \left(\mathrm{CV}^{2}+1\right)}\right]
$$

Com os CDCs obtidos, foi possível obter valores de projetos ou operações necessárias para que o efluente atingisse a meta especificada através da Equação 4.

$\mathrm{m}_{\mathrm{x}}=\mathrm{CDC} \cdot \mathrm{X}_{\mathrm{s}}$

Equação 4

Onde:

$\mathrm{m}_{\mathrm{x}}=$ concentração média do constituinte.

A metodologia para determinação das concentrações médias para serem alcançadas em operação seguiram os passos descritos no fluxograma da Figura 4.

Figura 4 - Etapas para cálculo das concentrações de projeto.

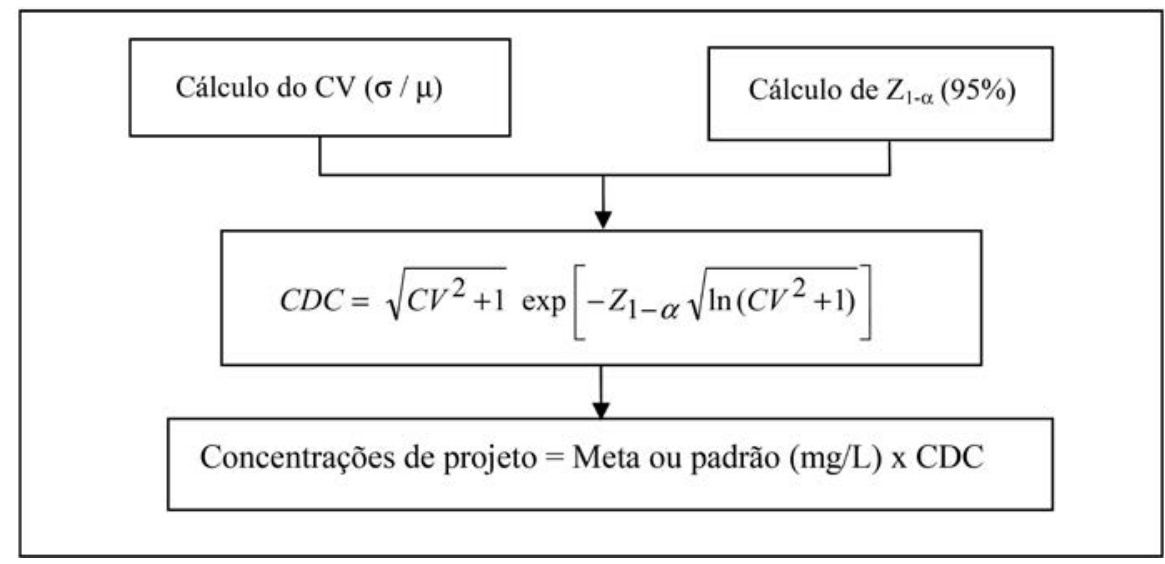

Fonte: Oliveira, 2006.

Para análise de confiabilidade, foram utilizados os parâmetros apresentados na Tabela 2 (exceto DBO, devido aos poucos dados), durante um período amostral de 24 meses (julho 2016 a julho de 2018), com frequência mensal.

Tabela 2 - Parâmetros estudados e respectivas metodologias para determinação dos parâmetros.

\begin{tabular}{l|l}
\hline Parâmetro & Metodologia \\
\hline DQO & 410.4 / USEPA (1993) \\
\hline Amônia & Standard Methods 4500 / APHA et al. (2012) \\
\hline Sólidos sedimentáveis & Standard Methods 2540 / APHA et al. (2012) \\
\hline Sólidos suspensos totais & Standard Methods 2540 D / APHA et al. (2012) \\
\hline
\end{tabular}

Fonte: Elaborado pelos autores, 2019.

\subsection{Remoção de outliers}

Como não havia interesse, nesta pesquisa, de checar situações extremas, mas, sim, de se conhecer o comportamento usual dos dados, optou-se, na presente análise, pela exclusão dos outliers. Então, empregouse um teste empírico utilizado por Silveira (2011). Esse teste incide na definição de limites inferior e superior. Esses limites são calculados aplicando o primeiro e o terceiro quartil da série de dados, designados de quartil inferior-percentil 25\%- $\left(Q_{i}\right)$ e superior-percentil 75\%- $\left(Q_{s}\right)$, respectivamente, como mostram as Equações 5 e 6. 


$$
\begin{array}{ll}
\text { Dado }<\mathrm{Q}_{i}-1,5 \times\left(\mathrm{Q}_{s}-Q_{i}\right) \rightarrow \text { Dispensar o dado } & \text { Equação } 5 \\
\text { Dado }>\mathrm{Q}_{s}+1,5 \times\left(\mathrm{Q}_{s}-Q_{i}\right) \rightarrow \text { Dispensar o dado } & \text { Equação } 6
\end{array}
$$

\subsection{Análises estatísticas}

A partir dos dados fornecidos pela Cagece, foi possível comparar as concentrações efluentes dos parâmetros (item 4.3.3) em cada uma das tecnologias estudadas, através do software Minitab® 18.1 (versão de avaliação), em que foram feitos os gráficos boxplots de cada parâmetro efluente de cada estação.

\subsection{Atendimento dos parâmetros da legislação}

Os valores limites das concentrações de amônia e DQO obedeceram a Portaria Semace n. ${ }^{\circ} 154$, de 22/07/2002, enquanto que, para os parâmetros sólidos sedimentáveis e sólidos suspensos totais, levou-se em conta os valores máximos determinados com base na Resolução Coema n. ${ }^{\circ}$ 02/2017. Elaboraram-se gráficos com as frequências acumuladas com percentis das concentrações dos parâmetros supracitados para verificar os percentuais de atendimento à legislação estadual. A Tabela 3 ilustra as concentrações máximas adotadas para cada parâmetro neste estudo.

Tabela 3 - Valores máximos permitidos.

\begin{tabular}{l|l|l|l}
\hline \multicolumn{2}{l|}{ COEMA 02/2017 } & \multicolumn{2}{l}{ SEMACE 154/2002 } \\
\hline Parâmetro & Valor & Parâmetro & Valor \\
\hline Amônia & Não especificado. & Amônia & $\leq 20 \mathrm{mg} / \mathrm{L}$ \\
\hline DQO & Não especificado. & DQO & $\leq 200 \mathrm{mg} / \mathrm{L}$ \\
\hline Sólidos Sedimentáveis & $\leq 1 \mathrm{ml} / \mathrm{L}$ & Sólidos Sedimentáveis & $\leq 1 \mathrm{ml} / \mathrm{L}$ \\
\hline Sólidos Suspensos Totais & $\leq 100 \mathrm{mg} / \mathrm{L}$ & Sólidos Suspensos Totais & $\leq 50 \mathrm{mg} / \mathrm{L}$ \\
\hline
\end{tabular}

Fonte: Adaptado de Coema (2017) e Semace (2002).

\section{Resultados e discussão}

\subsection{Remoção de DQO}

Os resultados médios da remoção de DQO da ETE 1, 2 e 3 estão apresentados nas Figuras 5, 6 e 7, respectivamente.

Figura 5 - Resultados da remoção de DQO da ETE 1 (UASB + FSA).

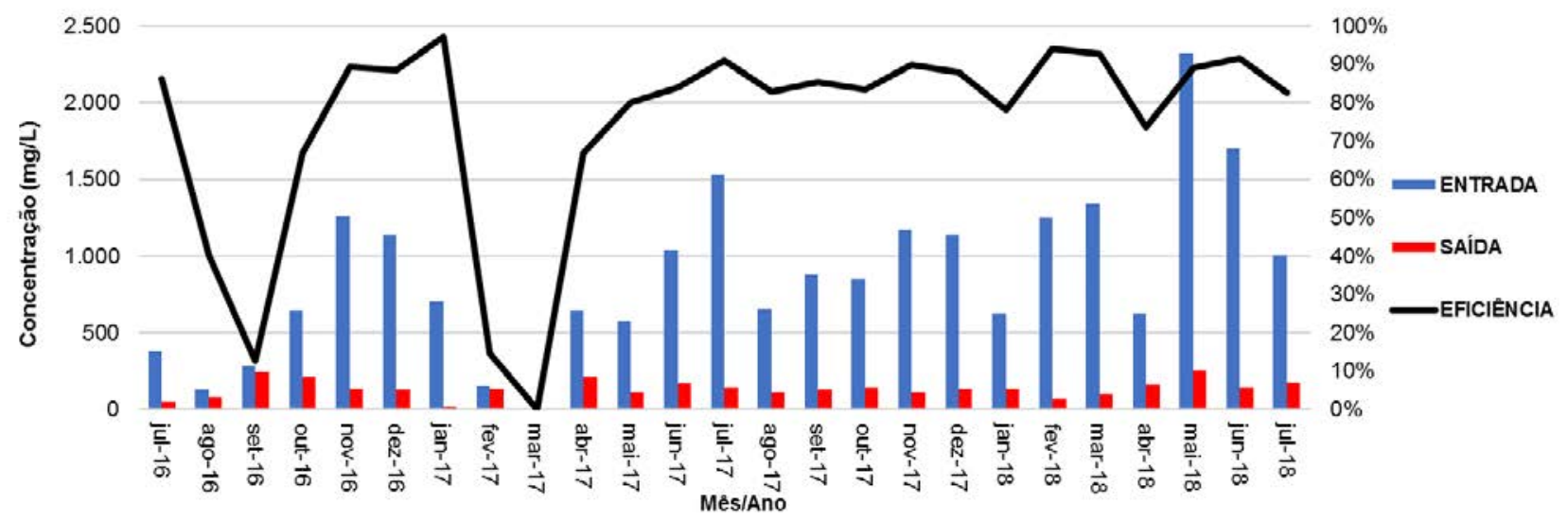

Fonte: Elaborado pelos autores, 2019. 
Figura 6 - Resultados da remoção de DQO da ETE 2 (DD + FA).

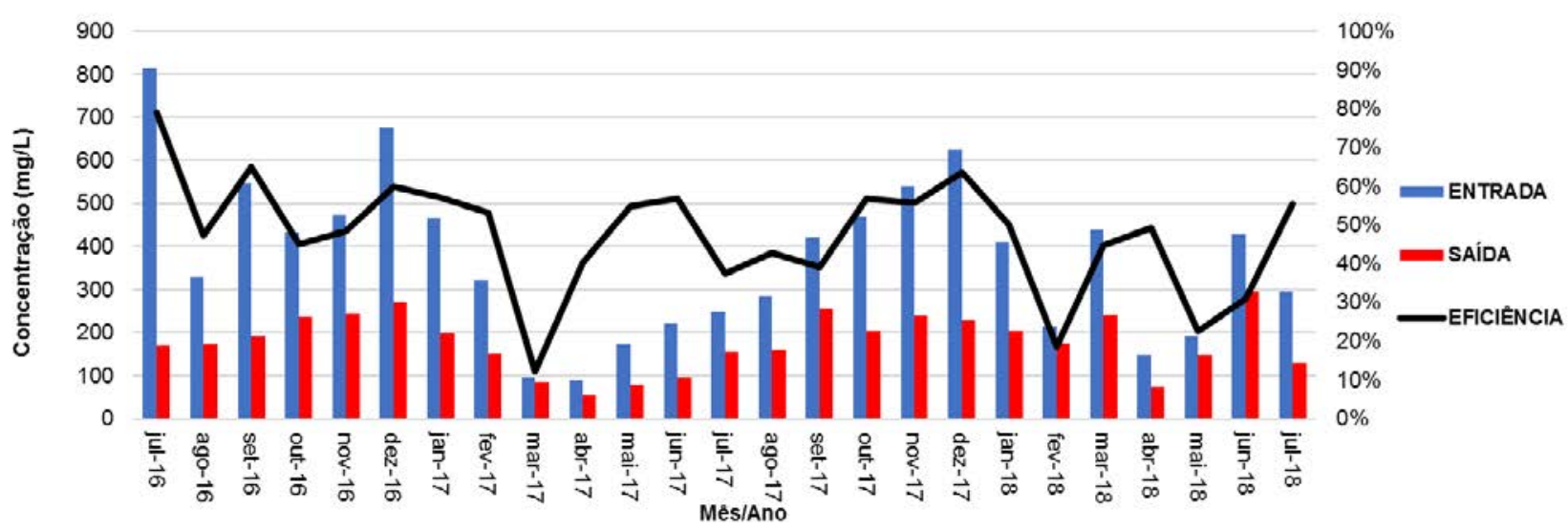

Fonte: Elaborado pelos autores, 2019.

Figura 7 - Resultados da remoção de DQO da ETE 3 (lodos ativados por aeração prolongada).

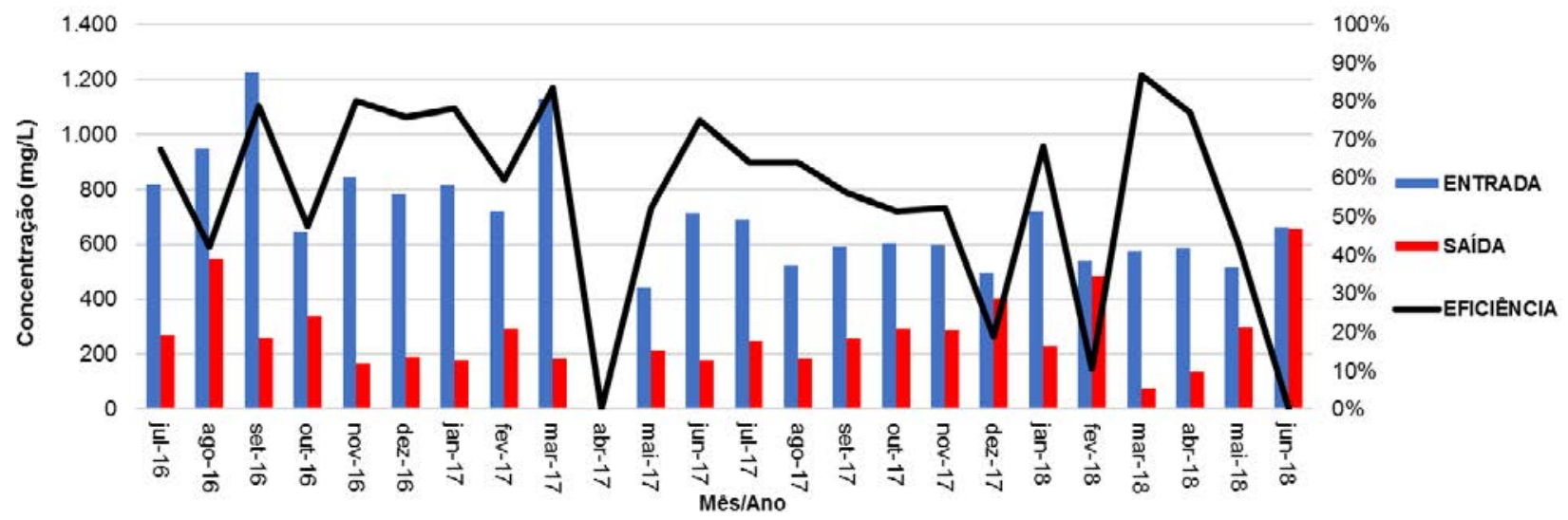

Fonte: Elaborado pelos autores, 2019.

Observa-se, nas Figuras 5, 6 e 7 que durante o período amostral (24 meses) houve alguns meses em que não se obteve dados amostrais, fato ocasionado por problemas operacionais. Os resultados mostraram que a ETE 1 (UASB + FSA) apresentou os melhores resultados de remoção ao parâmetro DQO, sendo observados valores superiores a $80 \%$ (quando se desconsidera outlier do mês de março/2017). A ETE 2 (DD + FA) apresentou os valores mais baixos de eficiência dentre as ETEs estudadas, com uma eficiência média de $47 \%$. Já a ETE 3 apresentou resultado intermediário de remoção de DQO em relação às outras ETEs, com média de $65 \%$ para o período analisado. Esses resultados eram esperados, já que a rota tecnológica da ETE 2 é considerada inapropriada para sistemas coletivos de tratamento, sendo utilizada, principalmente, em sistemas individuais (VON SPERLING, 2014). No entanto, devido a problemas financeiros e investimentos insuficientes, muitas ETEs ainda continuam a operar com sistemas DD+FA.

A Figura 8 mostra as concentrações de DQO efluente ao tratamento de cada tecnologia. Conforme pode ser observado, a ETE 1 (UASB+FSA) alcançou um efluente de melhor qualidade (137 mg/L) e melhor homogeneidade dos dados. 
Figura 8 - Concentrações DQO efluente.

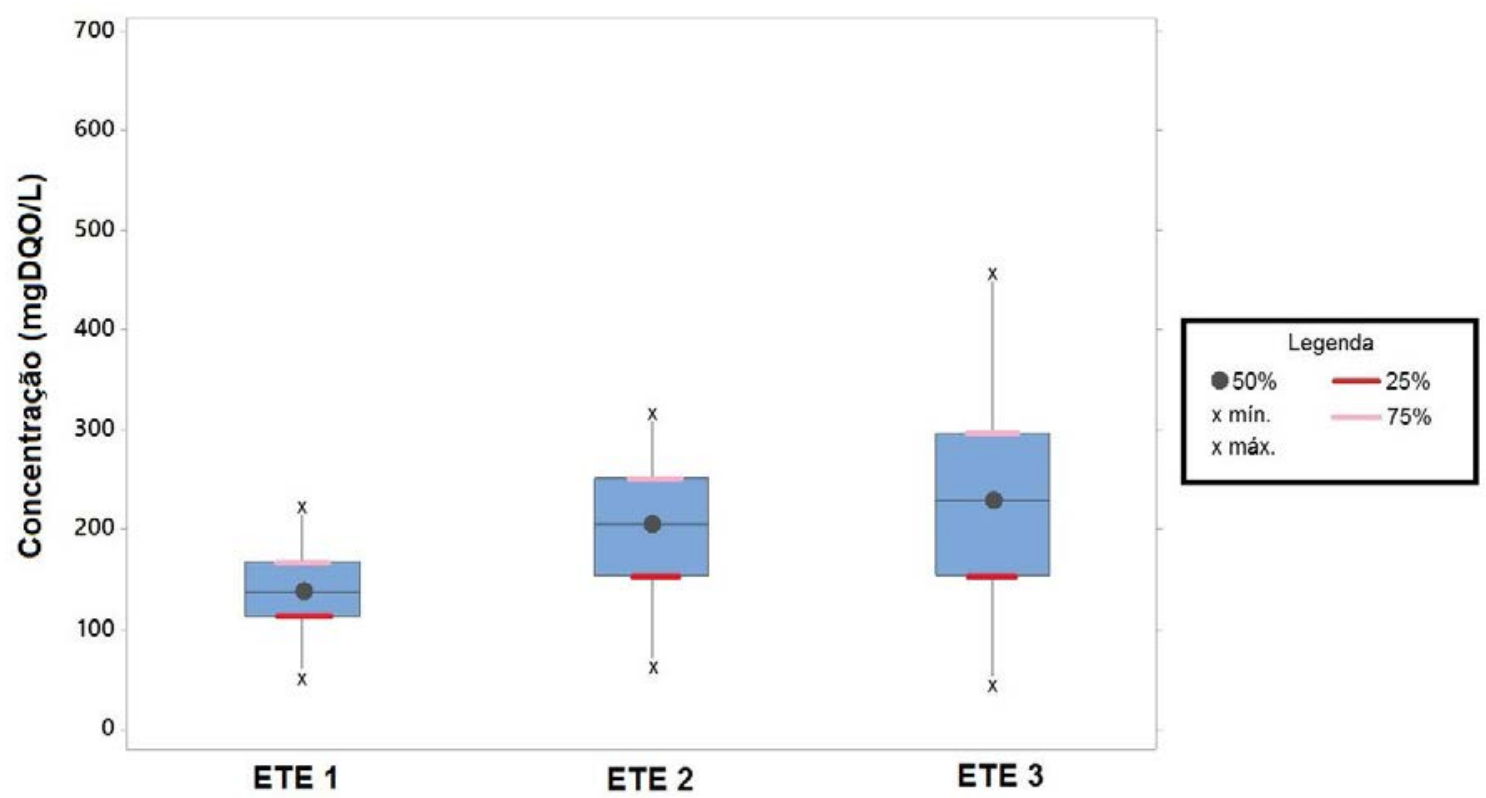

Fonte: Elaborado pelos autores, 2019.

\subsection{Remoção de amônia}

A Figura 9 mostra o boxplot da quantidade de amônia efluente nas tecnologias estudadas. Conforme observado na figura, nos sistemas UASB+FSA (ETE 1) e DD+FA (ETE 2) foram encontrados maiores concentrações médias e menor homogeneidade do parâmetro. A tecnologia da ETE 3 (Lodos ativados) apresentou melhores resultados na remoção de amônia, o que, de certa forma, era esperado, já que essa tecnologia favorece a ação de bactérias nitrificantes, corroborando com resultados encontrados por Alderson; Santos e Filho (2015).

Figura 9 - Concentrações de amônia efluente.

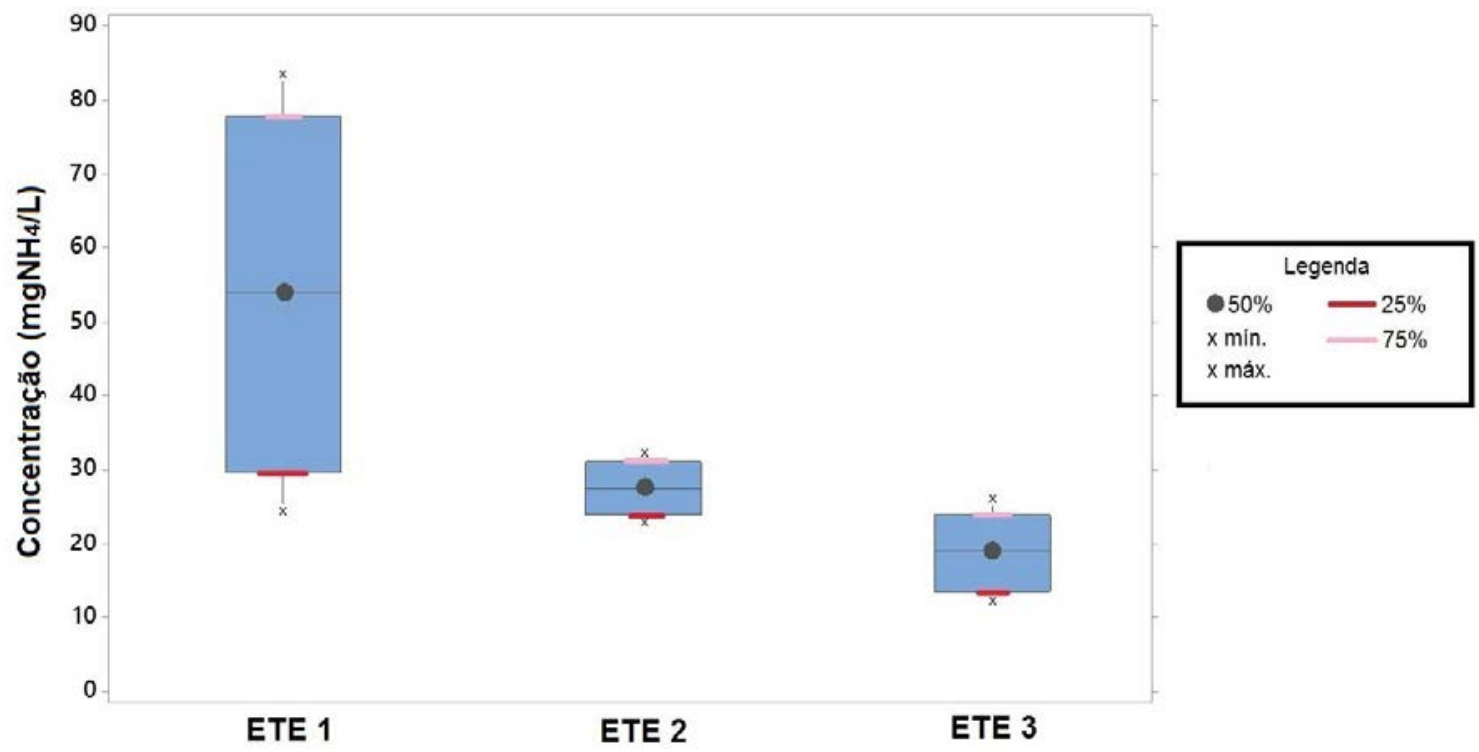

Fonte: Elaborado pelos autores, 2019. 


\subsection{Remoção de sólidos sedimentáveis}

A Figura 10 apresenta as concentrações de sólidos sedimentáveis após o tratamento das ETEs estudadas. Pela figura, é possível identificar que a tecnologia de lodos ativados possui maior concentração média $(9 \mathrm{ml} / \mathrm{L})$ de sólidos sedimentáveis. A comparação também está em conformidade com o que é reportado na literatura, ressaltando que a tecnologia de LA, por ser aeróbia, ocasiona a maior produção de lodo quando comparada a outras rotas de tratamento (JORDÃO e PESSÔA, 2017; METCALF e EDDY, 2016; VON SPERLING, 2016a).

Figura 10 - Concentrações de sólidos sedimentáveis efluente.

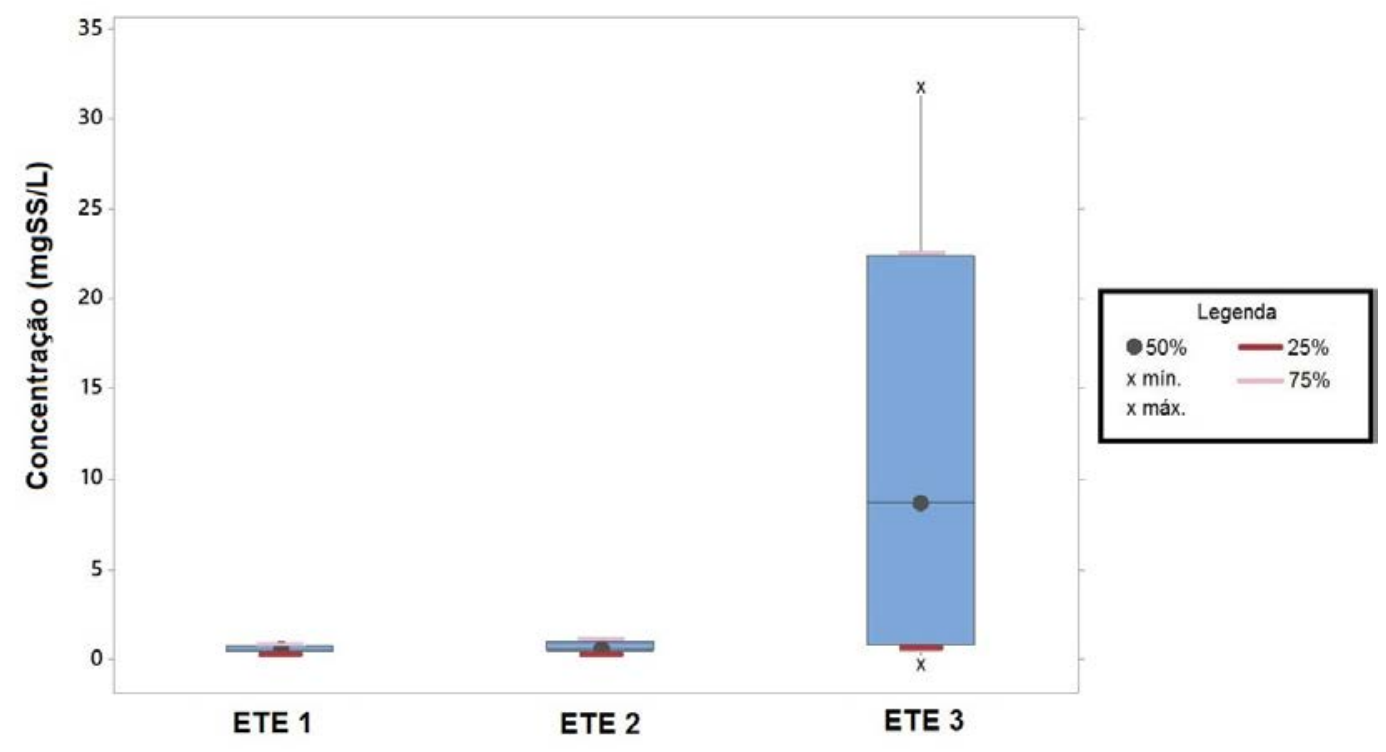

Fonte: Elaborado pelos autores, 2019.

\subsection{Remoção de sólidos suspensos totais}

Em relação ao parâmetro SST, a Figura 11 ilustra o boxplot das concentrações das estações em estudo.

Figura 11 - Concentrações de SST efluente final das ETEs estudadas.

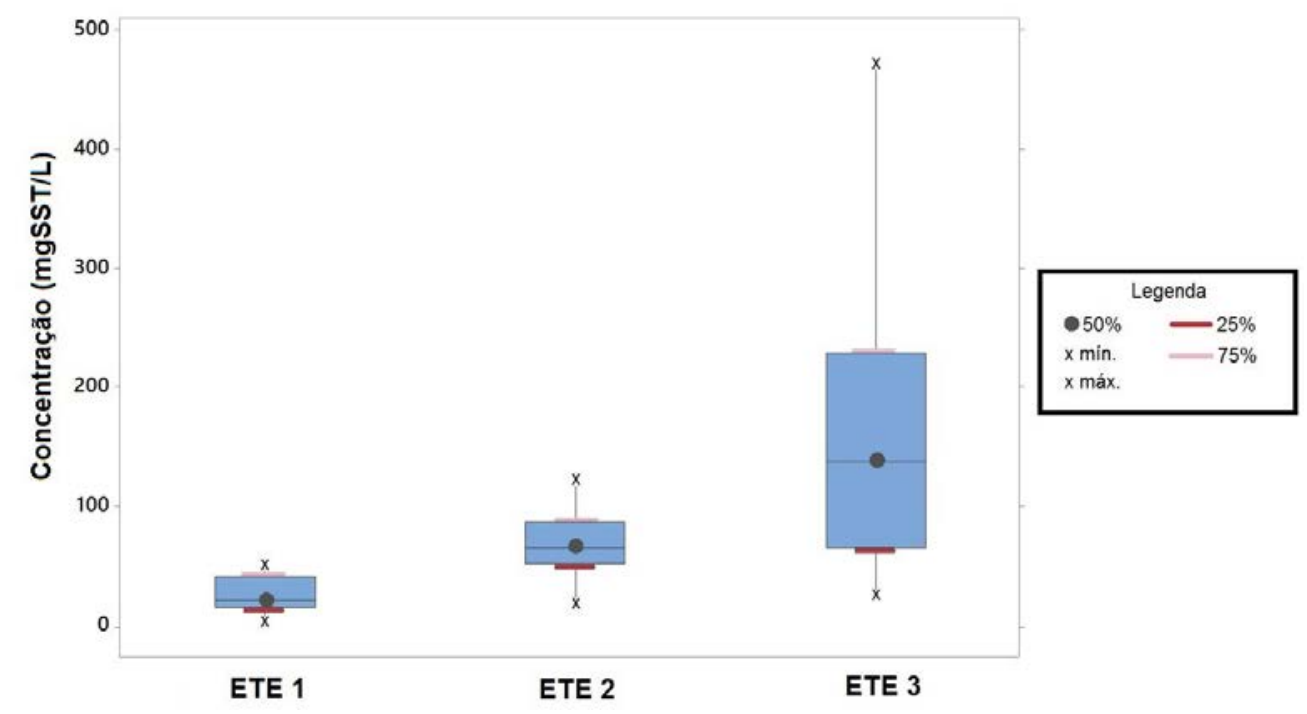

Fonte: Elaborado pelos autores, 2019. 
Observa-se, na Figura 11, que somente a estação com tecnologia de lodos ativados (ETE 3) ocorreram concentrações medianas maiores que a máxima permitida pela legislação estadual (130 mgSST/L). A explicação para esse fenômeno pode ser atribuída a problemas operacionais nos decantadores secundários, como falta de limpeza. As concentrações de SST, como mantém maior carga de sólidos orgânicos voláteis, colabora para o aumento de DQO efluente posteriormente. As demais estações tiveram concentrações médias abaixo do valor máximo da legislação (JORDÃO, PESSÔA, 2017; METCALF, EDDY, 2016; VON SPERLING, 2016a).

As concentrações médias do parâmetro para as ETEs estudadas variaram de 32 mgSST/L (ETE 1) a $154 \mathrm{mgSST} / \mathrm{L}$ (ETE 3).

\subsection{Atendimento aos padrões de lançamento}

\subsubsection{DQO}

De acordo com a Figura 12, analisa-se que a ETE 1 obteve as concentrações de DQO em $88 \%$ do tempo abaixo do valor máximo adotado na Tabela 3. Entretanto o desempenho da ETE 3 foi o pior entre as tecnologias estudadas, com atendimento desse parâmetro em apenas 33\% do tempo de estudo; ressaltando, assim, problemas operacionais.

Figura 12 - Valores de percentis para parâmetro DQO nas ETEs estudadas.

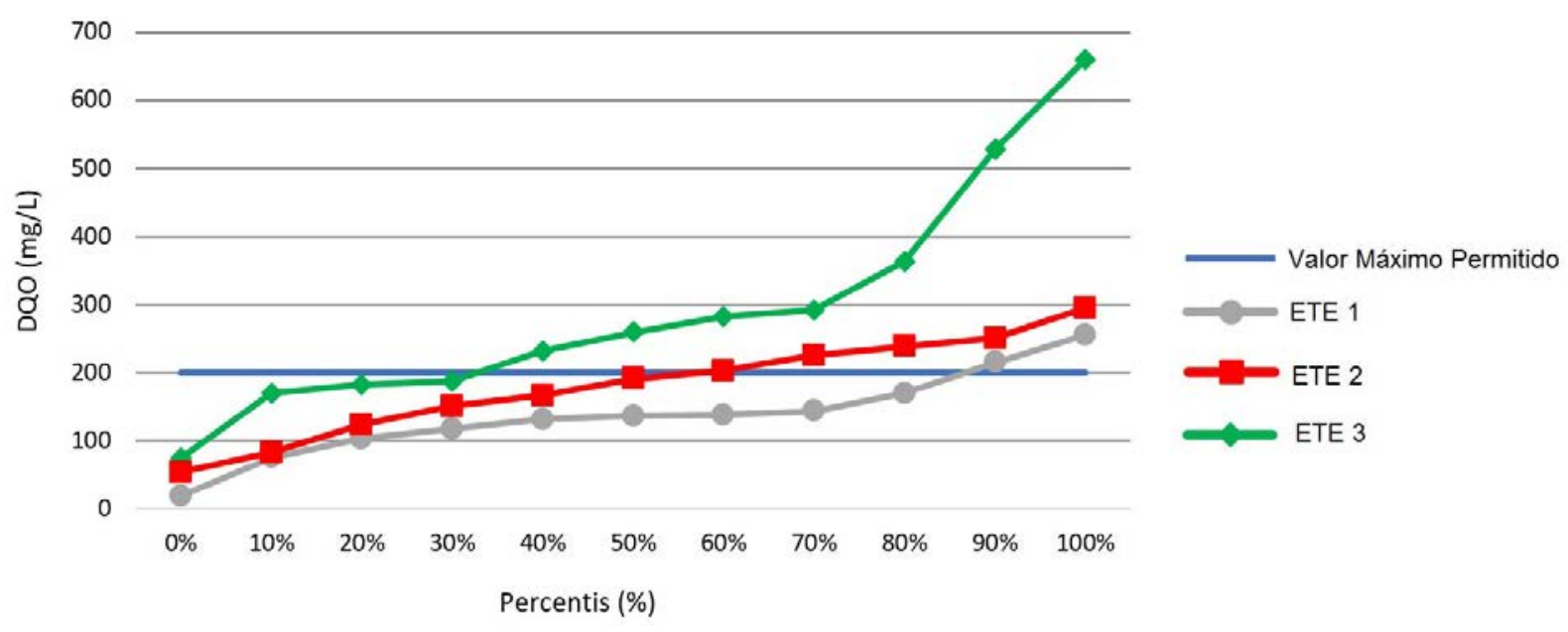

Fonte: Elaborado pelos autores, 2019.

\subsubsection{Amônia}

Para a concentração de amônia, conforme mostrado na Figura 13, as ETEs que adotaram tecnologia anaeróbia em alguma da rota de tratamento do efluente apresentaram, em 100\% do tempo, resultados acima dos permitidos pela legislação, ressaltando uma etapa para remoção desse composto e, por conseguinte, o atendimento a legislação. A ETE 3, por adotar uma rota de oxigenação bem superior as demais, conseguiu em $90 \%$ obter as concentrações do valor máximo. 
Figura 13 - Valores de percentis para o parâmetro amônia nas ETEs estudadas.

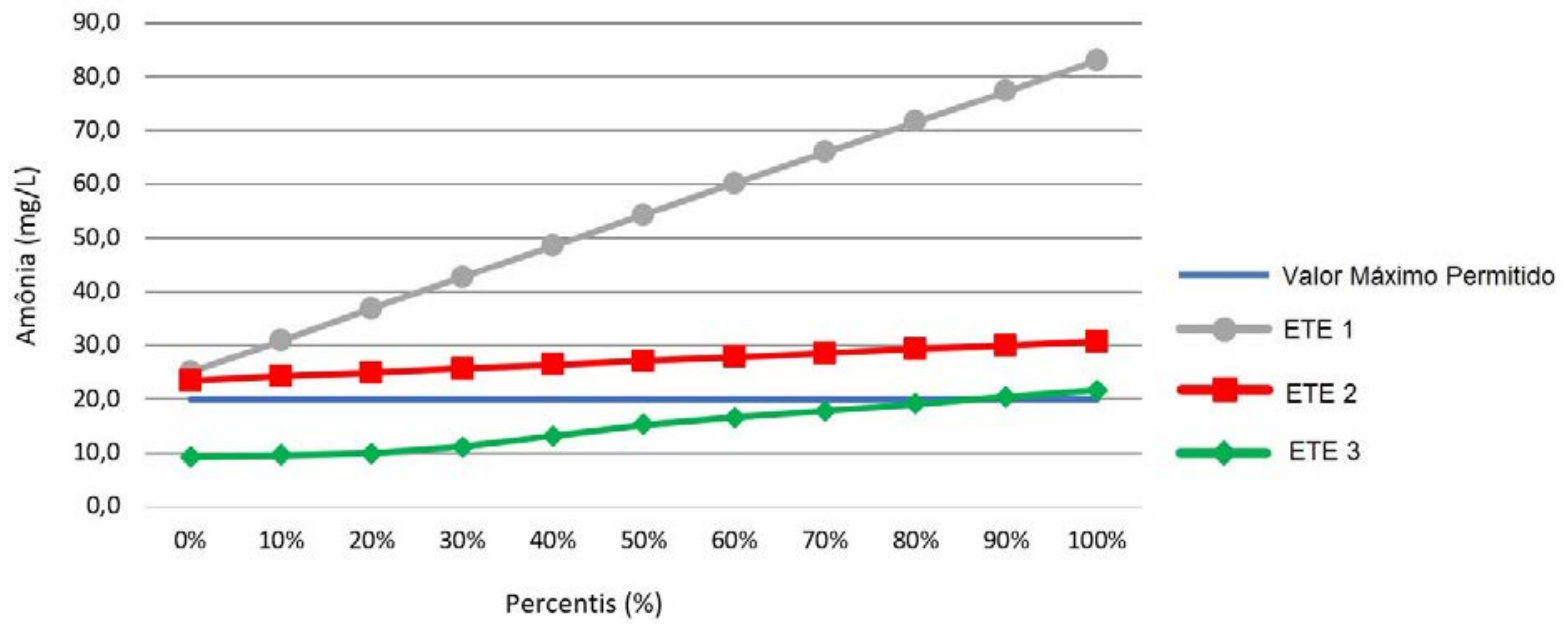

Fonte: Elaborado pelos autores, 2019.

\subsubsection{Sólidos sedimentáveis}

De acordo com a Figura 14, a ETE 3 apresentou, em 95\% do tempo de estudo, valores de SS superiores aos máximos permitidos na Resolução Coema $n .^{\circ}$ 02/2017, evidenciando possíveis problemas operacionais no decantador secundário dessa estação. Constata-se, ainda, na Figura 14 que as ETEs 1 e 2, em 100\% do tempo analisado, mantiveram as concentrações desse parâmetro abaixo do valor máximo, evidenciando positivamente o desempenho operacional dessas estações.

Figura 14 - Valores de percentis para parâmetro SS nas ETEs estudadas.

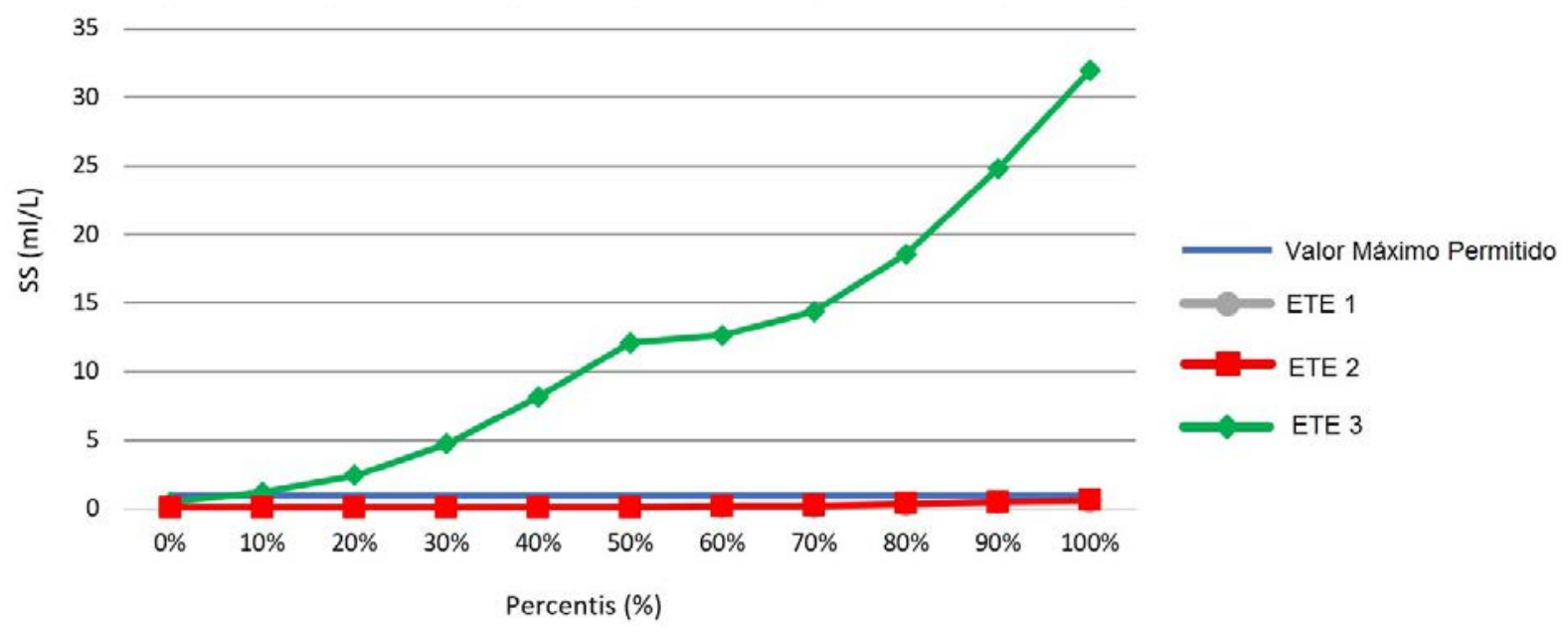

Fonte: Elaborado pelos autores, 2019.

\subsubsection{Sólidos suspensos totais}

Com relação ao parâmetro SST, observa-se, na Figura 15, que as tecnologias UASB + FSA e DD + FA atenderam aos padrões de lançamento em mais de $90 \%$ do tempo. Nota-se que a ETE 3 demostrou um desempenho insatisfatório em $55 \%$ do tempo de análise, frisando problemas no decantador secundário dessa estação. 
Figura 15 - Valores de percentis para parâmetro SST nas ETEs estudadas.

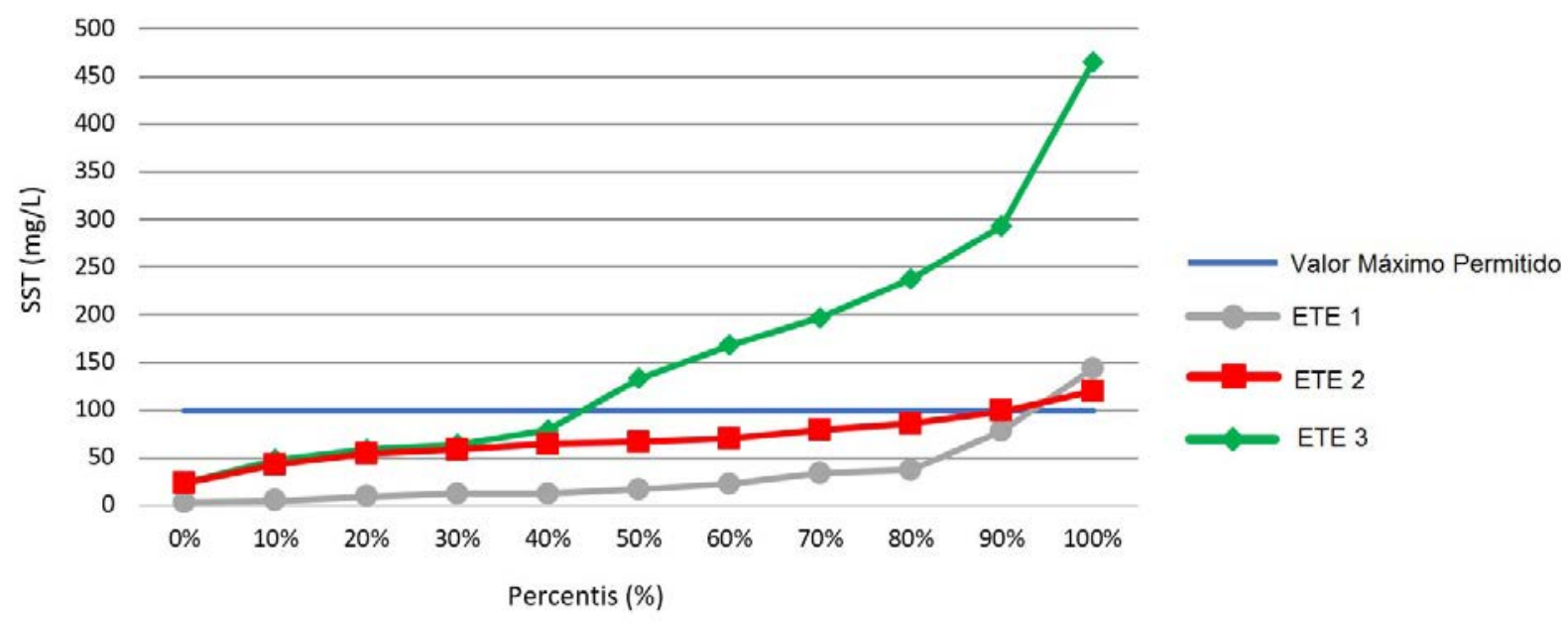

Fonte: Elaborado pelos autores, 2019.

\subsection{Análises de confiabilidade}

Em todos os parâmetros estudados, assumiu-se uma distribuição lognormal, pois esse modelo de distribuição, segundo Oliveira e Von Sperling (2007), mostra-se como melhor adequado para análises de confiabilidade. Nessa etapa da pesquisa, foram calculados os CDCs e as concentrações médias efluentes para o nível de confiabilidade adotado (95\%) para as ETEs estudadas, valor de confiabilidade congruente a estudos de ETEs (OLIVEIRA, 2006).

A Tabela 4 mostra os valores das variáveis CDC e $m_{x}$ calculados relacionados ao CV das ETEs para um nível de confiabilidade de $95 \%$ das ETEs em relação à remoção de DQO.

Tabela 4 - Valores de CDC e $m_{x}$ para o parâmetro DQO.

\begin{tabular}{l|l|l|l|l|l}
\hline $\mathbf{9 5 \%}$ nível de confiabilidade & $\boldsymbol{\mu} \mathbf{( \mathbf { m g } / \mathbf { L } )}$ & $\mathbf{C V}$ & $\mathbf{C D C}$ & $\mathbf{m}_{\mathbf{x}}(\mathbf{m g} / \mathbf{L})$ & Valor Máximo $(\mathbf{m g} / \mathbf{L})$ \\
\hline ETE & 138,73 & 0,41 & 0,56 & 112,43 & 200 \\
\hline ETE 1 & 179,81 & 0,36 & 0,60 & 119,31 & 200 \\
\hline ETE 2 & 286,33 & 0,49 & 0,52 & 103,95 & 200 \\
\hline ETE 3 &
\end{tabular}

Fonte: Elaborado pelos autores, 2019.

Observa-se, na Tabela 4, que a ETE 3 foi a única com a concentração média ( $\mu=286 \mathrm{mg} \mathrm{DQO} / \mathrm{L}$ ) maior que o valor máximo permitido em norma, aspecto também observado por Monteiro (2009) em estudo de uma ETE com rota tecnológica similar. Nesse contexto, a Tabela 5 apresenta os valores de CDC, $\mu, \mathrm{CV}$ e $\mathrm{m}_{\mathrm{x}}$ calculados para a remoção de sólidos suspensos totais.

Tabela 5 - Coeficiente de confiabilidade das ETEs tratando SST.

\begin{tabular}{l|l|l|l|l|l}
\hline $\mathbf{9 5 \%}$ nível de confiabilidade & $\boldsymbol{\mu}(\mathbf{m g} / \mathbf{L})$ & $\mathbf{C V}$ & $\mathbf{C D C}$ & $\mathbf{m}_{\mathbf{x}}(\mathbf{m g} / \mathbf{L})$ & Valor Máximo $(\mathbf{m g} / \mathbf{L})$ \\
\hline ETE & 32,52 & 1,11 & 0,34 & 34,28 & 100 \\
\hline ETE 1 & 68,48 & 0,31 & 0,64 & 63,76 & 100 \\
\hline ETE 2 & 154,10 & 0,78 & 0,41 & 40,90 & 100 \\
\hline ETE 3 &
\end{tabular}

Fonte: Elaborado pelos autores, 2019. 
Pode-se identificar, na Tabela 5, que a ETE 1 obteve as concentrações médias de sólidos suspensos totais ( $\mu=32,52 \mathrm{mgSST} / \mathrm{L}$ ) bem próximo da concentração ideal para um nível de confiabilidade de 95\% (34,28 $\mathrm{mg} / \mathrm{L})$. Não obstante, a ETE 3 precisaria obter em 95\% um valor ideal de concentração de 40,90 mg/L para o referido parâmetro. Em relação à ETE 2, Alderson; Santos e Filho, Santos e Filho (2015), estudando análise de confiabilidade de estações no Ceará, encontraram valores ( $\mu=66 \mathrm{mgSST} / \mathrm{L}$ e $\left.\mathrm{m}_{\mathrm{x}}=55 \mathrm{mgSST} / \mathrm{L}\right)$ próximos para rota tecnológica similar.

Para o parâmetro de amônia, a Tabela 6 mostra os resultados obtidos neste estudo.

Tabela 6 - Coeficiente de confiabilidade das ETEs tratando amônia.

\begin{tabular}{l|l|l|l|l|l}
\hline $95 \%$ nível de confiabilidade \\
\hline ETE & $\boldsymbol{\mu}(\mathbf{m g} / \mathbf{L})$ & CV & CDC & $\mathbf{m}_{\mathbf{x}}(\mathbf{m g} / \mathbf{L})$ & Valor máximo $(\mathbf{m g} / \mathbf{L})$ \\
\hline ETE 1 & 63,80 & 0,15 & 0,81 & 16,15 & 20 \\
\hline ETE 2 & 27,14 & 0,12 & 0,99 & 19,88 & 20 \\
\hline ETE 3 & 14,08 & 0,14 & 0,77 & 15,01 & 20 \\
\hline
\end{tabular}

Fonte: Elaborado pelos autores, 2019.

$\mathrm{Na}$ Tabela 6 observa-se que o maior valor $m_{x}$ (concentração ideal) foi para a ETE com tecnologia de decanto digestor (DD). Para um nível de confiança de 95\%, a estação deveria produzir um efluente com concentração de, no máximo, 19,88 mg/L para estar adequada aos padrões da legislação estadual. Observase, ainda na Tabela 6, que a concentração média de amônia na ETE 3 foi menor que a concentração ideal para confiabilidade de $95 \%$, ressaltando a escolha dessa rota tecnológica para atendimento a esse parâmetro. As estações que incorporaram a tecnologia anaeróbia não trataram eficazmente amônia. Para o parâmetro de sólidos sedimentáveis, a Tabela 7 apresenta os resultados obtidos neste estudo.

Tabela 7 - Coeficiente de confiabilidade das ETEs tratando sólidos sedimentáveis.

\begin{tabular}{l|l|l|l|l|l}
\hline $\mathbf{9 5 \%}$ nível de confiabilidade & \multicolumn{5}{l}{} \\
\hline ETE & $\boldsymbol{\mu}(\mathbf{m l} / \mathbf{L})$ & $\mathbf{C V}$ & CDC & $\mathbf{m}_{\mathbf{x}}(\mathbf{m l} / \mathbf{L})$ & Valor Máximo $(\mathbf{m l} / \mathbf{L})$ \\
\hline ETE 1 & 0,19 & 0,93 & 0,26 & 0,26 & 1 \\
\hline ETE 2 & 0,27 & 0,64 & 0,41 & 0,41 & 1 \\
\hline ETE 3 & 10,77 & 1,06 & 0,33 & 0,33 & 1 \\
\hline
\end{tabular}

Fonte: Elaborado pelos autores, 2019.

O maior valor de CV, segundo a Tabela 7, foi o da ETE 3, que deveria produzir um efluente com concentração ideal de $0,33 \mathrm{ml} / \mathrm{L}$ para atendimento à legislação estadual, com média atual de 10,77 ml/L. A única tecnologia para esse parâmetro que conseguiu produzir um efluente com qualidade média abaixo do valor ideal foi a ETE 1 (UASB+FSA).

\section{Conclusão}

A pesquisa analisou os desempenhos das estações de tratamento de forma individual, ou seja, uma única estação por tipo de tratamento, empregando as eficiências médias de remoção de DQO, SS, SST e amônia. Além disso, foram avaliados os coeficientes de confiabilidade, analisando a eficiência das ETEs quanto aos padrões de lançamento e, consequentemente, ao alcance das metas de qualidade, considerando um nível de confiabilidade de $95 \%$. Foi observado nesse neste trabalho que, em relação ao parâmetro amônia, as ETEs que utilizaram as rotas com tecnologia anaeróbia não conseguiram, em nenhum momento, atingir os valores abaixo do adotado pela legislação. Analisou-se, também, que, para a remoção da matéria orgânica em termos de DQO, a estação com tecnologia UASB+FSA obteve o melhor desempenho entre as demais. Por fim, foi 
notado que a análise de confiabilidade pode ser utilizada como uma importante ferramenta para avaliação de desempenho de sistemas de tratamento de esgoto.

\section{Referências}

ALDERSON, M. P; SANTOS, A. B; MOTA FILHO, C. R. Reliability analysis of low-cost, full-scale domestic wastewater treatment plants for reuse in aquaculture and agriculture. Ecological Engineering, [s. I.], v. 82, p. 6-14, set. 2015. DOI: 10.1016/j.ecoleng.2015.04.081. Disponível em: https://www.sciencedirect.com/ science/article/pii/S0925857415001913. Acesso em: 05 set. 2018.

AMERICAN PUBLIC HEALTH ASSOCIATION. Standard methods for the examination of water and wastewater. 22. ed. Washington: APHA, 2012.

BASTOS, R. K. X; et al. E. Caracterização e tratamento de diferentes tipos de águas residuárias de origem de origem residencial após segregação. In: CONGRESO INTERAMERICANO DE INGENIERÍA SANITARIA Y AMBIENTAL, 30, 2006 26-30 nov. Punta del Este. Anais [...]. Montevideo: AIDIS, 2006. p. 1-8.

CEARÁ. Conselho Estadual de Meio Ambiente. Resolução $\mathbf{n}^{\circ}$ 02, de 02 de fevereiro de 2017. Dispõe Sobre Padrões e Condições PARA lançamento de Efluentes Líquidos Gerados por Fontes Poluidoras, Revoga as Portarias SEMACE №154, de 22 de julho de 2002 e №111, de 05 de abril de 2011, e Altera a Portaria SEMACE n 151, de 25 de novembro de 2002. Fortaleza, CE, 21 fev. 2017. Disponível em: https:// www.legisweb.com.br/legislacao/?id=337973. Acesso em: 05 set. 2018.

JORDÃO, E. P; PESSÔA, C. A. Tratamento de esgotos domésticos. 8. ed. Rio de Janeiro: ABES, 2017.

LOMBARD-LATUNE, R. et al. Resilience and reliability of compact vertical-flow treatment wetlands designed for tropical climates. Science of the Total Environment, [s. I.], v. 642, p. 208-215, nov. 2018. DOI: 10.1016/j.scitotenv.2018.06.036. Disponível em: https://www.sciencedirect.com/science/article/pii/ S0048969718320989. Acesso em: 21 mar. 2019.

METCALF, L.; EDDY, H. P. Tratamento de efluentes e recuperação de recursos. Tradução de Ivanildo Hespanhol e José Carlos Mierzwa. 5. ed. Porto Alegre: AMGH, 2016.

MONTEIRO, C. R. L. Análise da eficiência e confiabilidade em 56 estações de tratamento de esgotos localizadas na região metropolitana de Fortaleza. 2009. 77 f. Dissertação (Mestrado em Engenharia Civil) - Centro de Tecnologia, Universidade Federal do Ceará, Fortaleza, 2009.

NIKU, S; SCHROEDER, E. D., SAMANIEGO, F. J. Performance of activated sludge processes and reliability-based design. Journal Water Pollution Control Federation, Estados Unidos v. 51, n. 12, p. 2841-2857, dez. 1979.

OLIVEIRA, S. M. A. C. Análise de desempenho e confiabilidade de estações de tratamento de esgotos. 2006. 77 f. Tese (Doutorado em Saneamento, Meio Ambiente e Recursos Hídricos) - Universidade Federal de Minas Gerais, Belo Horizonte, 2006.

OLIVEIRA, S. M. A. C; VON SPERLING, M. Análise da confiabilidade de estações de tratamento de esgotos. Engenharia sanitária e ambiental, Belo Horizonte, v. 12, n. 4, p. 389-398, out./dez. 2007.

OLIVEIRA, S. M. A. C; VON SPERLING, M. Reliability analysis of wastewater treatment plants. Water Research, [s. I.], v. 42, p. 1182-1194, fev. 2008. DOI: 10.1016/j.watres.2007.09.001. Disponível em: https:// www.sciencedirect.com/science/article/pii/S0043135407005854. Acesso em: 29 jan. 2019.

SANTOS, A. B. Avaliação técnica de sistemas de tratamento de esgotos. Fortaleza: Banco do Nordeste do Brasil, 2007. 
SILVEIRA, A. G. M. Análise de eficiência e confiabilidade em sistemas de baixo custo de tratamento do tipo lagoas de estabilização. Disponível em: http://www.repositorio.ufc.br/handle/riufc/4766. Acesso em: 10 set. 2018.

SUPERINTENDÊNCIA ESTADUAL DO MEIO AMBIENTE. Portaria n 154, de 22 de junho de 2002. Dispõe sobre padrões e condições para lançamento de efluentes líquidos gerados por fontes poluidoras. Fortaleza: SEMACE, 2002.

VON SPERLING, M. Princípios do tratamento biológico de águas residuárias. 4. ed. Belo Horizonte: UFMG, 2014. v. 1.

VON SPERLING, M. Princípios do tratamento biológico de águas residuárias. 4. ed. Belo Horizonte: UFMG, 2016. v. 4.

\section{Sobre os autores}

Francisco de Assis Martins Ponce

Atualmente, é mestrando no Programa de Pós-graduação em Engenharia Hidráulica e Saneamento da Universidade de São Paulo. Engenheiro ambiental e sanitarista pela Universidade de Fortaleza - 2018. Experiente em tratamento biológico de efluentes, redes de abastecimento de água e esgotamento sanitário, projeto de aterro sanitário e planos municipais de saneamento básico. Tem interesse de pesquisa na área de tratamento biológico de efluentes domésticos/ industriais, principalmente no emprego de tecnologias anaeróbias/aeróbiasn como também se interessa pela eficiência de remoção de compostos orgânicos e biológicos das unidades componentes do tratamento, além da recuperação de subprodutos gerados. Participa do programa Jovens Profissionais do Saneamento, da ABES-CE, coordenando o programa. Foi estagiário da Agência Reguladora do Estado do Ceará, onde realizou atividades de fiscalização de planos municipais de saneamento básico e dos sistemas de abastecimento de água e coleta de esgoto do estado do Ceará.

\section{Silvio Luiz de Sousa Rollemberg}

Mestre em Desenvolvimento e Meio Ambiente (Conceito CAPES 5) pela Universidade Federal do Ceará, UFC, Brasil - 2017. Doutorando em Engenharia Civil (Recursos Hídricos) (Conceito CAPES 7) na Universidade Federal do Ceará, UFC, Brasil - 2017. Engenheiro sanitarista e ambiental com experiência em projetos e execuções de instalações hidrossanitárias, redes de abastecimento de água e esgotamento sanitário, sistemas drenagem urbana e outros. Atualmente, dedica-se à pesquisa de tecnologias emergentes de tratamento de águas residuárias.

\section{Andre Gadelha de Oliveira}

Doutorado em Química pela Universidade Federal do Ceará, UFC - 2018, com período de um ano na NHL University of Applied Sciences, Leeuwarden - HOL. Atualmente é professor da Universidade de Fortaleza - Unifor. Mestrado em Engenharia Civil (Saneamento Ambiental) pela Universidade Federal do Ceará, UFC - 2011. Possui graduação em Química Bacharel pela Universidade Federal do Ceará, UFC - 2007. Tem experiência na área de Química e Saneamento Ambiental, com ênfase em química analítica, tratamento de água/efluentes, processos oxidativos avançados, adsorção, e qualidade de água.

Recebido em: 02/02/2019

Aceito em: 10/06/2019 